\title{
Do agreements between adolescent and parent reports on family socioeconomic status vary with household financial stress?
}

\author{
Christy Pu', Nicole Huang ${ }^{1}$ and Yiing-Jenq Chou $^{2 *}$
}

\begin{abstract}
Background: Many studies compared the degree of concordance between adolescents' and parents' reports on family socioeconomic status (SES). However, none of these studies analyzed whether the degree of concordance varies by different levels of household financial stress. This research examines whether the degree of concordance between adolescents' and parent reports for the three traditional SES measures (parental education, parental occupation and household income) varied with parent-reported household financial stress and relative standard of living.
\end{abstract}

Methods: 2,593 adolescents with a mean age of 13 years, and one of their corresponding parents from the Taiwan Longitudinal Youth Project conducted in 2000 were analyzed. Consistency of adolescents' and parents' reports on parental educational attainment, parental occupation and household income were examined by parent-reported household financial stress and relative standard of living.

Results: Parent-reported SES variables are closely associated with family financial stress. For all levels of household financial stress, the degree of concordance between adolescent's and parent's reports are highest for parental education ( $\kappa$ ranging from 0.87 to 0.71 ) followed by parental occupation ( $\kappa$ ranging from 0.50 to 0.34 ) and household income ( $\kappa$ ranging from 0.43 to 0.31 ). Concordance for father's education and parental occupation decreases with higher parent-reported financial stress. This phenomenon was less significant for parent-reported relative standard of living.

Conclusions: Though the agreement between adolescents' and parents' reports on the three SES measures is generally judged to be good in most cases, using adolescents reports for family SES may still be biased if analysis is not stratified by family financial stress.

\section{Background}

Socioeconomic status (SES) is an important component in studies that investigates health disparities for adolescents, as SES is associated with many health behaviors as well as health outcomes for adolescents [1-5]. The validity of the results from these studies depend on the accuracy of these SES measures. Previous studies that compare concordance between adolescent and parentreported SES however, have ignored whether such concordances are in fact affected by household financial stress [6-9].

\footnotetext{
* Correspondence: yjchou@ym.edu.tw

${ }^{2}$ Department of Public Health, School of Medicine, National Yang-Ming

University, Taipei, Taiwan

Full list of author information is available at the end of the article
}

Household income, parents' educational attainment and occupation class are most commonly used to measure SES for adolescents, and it has been argued that adolescents are unable to report these variables accurately. Wardle et al.[10] found in a sample of 1,824 adolescents that was comprised mainly of girls, approximately $16 \%$ of the subjects either did not or could not determine their parents' occupation, and approximately $25 \%$ of the subject could not answer whether their parents have a college degree. Similarly, Currie et al.[11] in a sample of 4,079 Scottish schoolchildren found that over $20 \%$ of $11-15$ year olds were unable to provide a substantive response on father's occupation. However, for studies that compare adolescent's own report on parental SES and that reported by the parents, most found

\section{Biomed Central}


moderate to good agreement depending on the SES measure in question. A study[6] used a Spanish sample of adolescents $(n=91)$ and found that percentage of agreement for parental education and occupation ranged from $63.6 \sim 87.7 \%$ (kappa statistic ranged from $0.39 \sim 0.77$ ). In another study of Norwegian sample $(\mathrm{n}=924)$, agreement of reports for parental occupation was judged to be acceptable (kappa ranging from $0.65 \sim 0.86$ ). Similar results were found by Vereecken and Vandegehuchte[7] (Flanders sample, $\mathrm{n}=235$ ).

However, it should be noted that degree of concordance between adolescent and parent reports on the SES variables may be different for households experiencing different levels of financial stress. Financial stress has been defined by most of the previous studies has whether the household has enough money to pay for its expenses or have money left over during a period of time before the survey. Respondents are normally asked to choose from a Likert scale response (for example, from more than enough to very short, or from a lot of difficulties to no difficulties, or from a lot of money left over to shortage)[12-15]. Household financial stress is important to look at because it reflects material availability and if concordance varies by actual economic resource of the household, then using proxy measures on these SES variables could lead to biases depending on the level of financial stress the household experiences.

Studies have shown that family financial stress plays important roles in adolescent's health and development $[12,13]$. Family financial stress has been shown to be associated with depressive symptoms, delinquency and drug use for adolescents $[14,16]$. A study indicated that family financial stress has adverse effect on adolescents' self-rated health[17]. In addition, family financial stress can lead to suicidal ideation for adolescents through its impact on parent's behavior (such as parental hostile behavior and physical abuse)[18]. It is unreasonable to assume that the degree of concordance for the SES measures is uniformly distributed by family financial stress, and if concordances of the SES measures vary by family financial stress, then estimates of SES disparities in adolescent health using traditional SES measures could be biased even in cases where high concordance between adolescent and parent's reports are found.

Studies have shown that while education, occupation and income have been widely used to measure SES, these three variables may behave very differently from each other in determining health behaviors and health outcomes[19-21]. Specifically, these three variables represent different aspects of social class[8]. In this research, we use all three measures of family SES to determine whether the degree of concordance vary by family financial stress.

\section{Methods \\ Data}

The Youth Project was a panel survey conducted by the Academia Sinica of Taiwan in 2000, which is a publicly released dataset. A multi-stage stratified sampling method was used for this study. The various criteria used for the sampling including urbanization degree, proportion of student population in each stratum, and mean student number of the class in each stratum. A total of 29 sub-regions were obtained. Classes were chosen at random within each stratum. Once a class is chosen, all students within the class as well as their parents were interviewed. Overall, 81 classes were chosen from 40 schools (16 from Taipei City, 15 from Taipei County and 9 from Yi-Lan County). The details of the survey design can be found elsewhere[22,23]. The survey consists of 2690 students who were in their first year of junior high school (mean age $=13$ years). Of the 2,690 adolescents, 27 of them did not have a matching parent questionnaire. For the remaining 2,663 adolescents, eight had a parent questionnaire returned but it was indicated by the adolescents that the questionnaires had been filled out by themselves, and thus were classified as without a matching parent questionnaire. Of the remaining 2,655 subjects, eight parent questionnaires indicated that the respondent was a grandparent and 37 indicated that the respondent was in "another" relationship with the child and 17 had missing values for the relationship question. Since the student questionnaire only asked for the mother and father's educational attainment and occupation, in order to be conservative, these 45 subjects were not included in the analysis for adolescent-parent agreement. This means that a total of 2,593 adolescents with a matching parent questionnaire that was filled out by the parent (either father or mother) were available for this study.

\section{SES measures}

The adolescents were asked the question "What is your father's occupation?", and in a separate question "What is your mother's occupation?". Both of these questions are open-ended and were coded based on standards developed by the Youth Project. Eventually the occupations were classified into (1) Managerial; (2) Professional; (3) Highly skilled; (4) Semi-skilled; (5) Agricultural workers; (6) Low skilled; (7) Unskilled; (8) Military; (9) Unemployed/not in job, and (10) Unable to classify. Category (9) included those who were unemployed, housewives, students, and those with no-wage jobs. Class (10) includes answers that only indicated the type of industry and were without a job title.

In the parent questionnaire, the questions "What is your occupation?" and "What is your spouse's occupation?" were asked. Both are open ended questions with a 
similar coding method to that mentioned above. The questionnaire also asked the responding parent to determine the relationship with the child, and the parent was able to choose from "Mother", "Father", "Grandparent" and "Other". The first two relationships (mother or father filling out the questionnaire) represented $97.3 \%$ of the entire sample.

The adolescents were asked to report the monthly household income, and the answer used a 12-category scale ranging from "Below NT $\$ 30,000$ " (approximately US $\$ 1,000$, based on the exchange rate NT $\$ 30=$ US\$1) to "Above NT\$150,000" (approximately US\$5,000). The parent was asked to report the monthly household income by an open ended question "The monthly household income of your family is approximately thousands of NT\$". The answer from the parent's report on this question was then coded into the same interval as the one from the adolescent questionnaire described above.

Finally, the adolescents were asked to report their father and mother's educational attainment using two separate questions, and the parents were asked to report their own as well as their spouse's educational attainment level. This variable consisted of six categories ranging from "primary school or below" to "graduate".

\section{Financial stress}

To see whether the degree of concordance vary by household financial stress, we included analyses using two parental perceived financial stress questions. The parents were asked the question "How has the financial status of your household been for the past year before the interview?" and the respondent can choose from "a lot surplus", "some surplus", "balanced" and "shortage". Asking for financial balances is a typical approach to measuring financial stress and has been used in many studies [15]. To measure relative financial stress, the parents were asked in a separate question "How is the current standard of living of your household compared with other households?" and the respondent can choose from "a lot better", "better", average", "worse" and "a lot worse".

\section{Statistical analysis}

Descriptive statistics were used to show distribution of the responses by adolescents and parents. We first compared the distribution of responses, including those with missing responses, for the three SES variables, namely mother and father's occupation, mother and father's educational attainment (Table 1) and household income (Table 2) for those with a matching parent questionnaire. The degree of agreement was analyzed using the weighted $\kappa$. Cohen's $\kappa$ has been widely used to compare answers for similar questions by different respondents [24-26]. For ordinal variables, weighted $\kappa$ should always be used so that partial credits are given to responses in the adjacent group but not in exact concordance[27]. Following Whiteman and Green[28], we weighted the $\kappa$ statistic by the square of the deviation from exact agreement. Such weights were applied to parental education and household income, since these two measures of SES have a clear ordered rank. No weight was applied to parental occupation since it is a multinomial variable. Guidelines for assessing the degree of agreement have been proposed as follows[8]: $0.8<\kappa \leqq 1$ (very good), 0.6 $<\kappa \leqq 0.8$ (good), $0.4<\kappa \leqq 0.6$ (moderate), $0.2<\kappa \leqq 0.4$ (fair) and $\kappa \leqq 0.2$ (poor).

The distributions of the parent-reported SES variables by levels of household financial stress are presented in Tables 3, 4, 5. We then compare the degree of concordance between adolescents' report and the parents' reports relative to the two parent-rated household financial stress questions (Table 6). It should be note that if both parties (adolescent and parent) had non-response, such non-responses may also be considered "consistent" between the two parties. Previous studies usually ignore cases with missing responses in calculating Cohen's $\kappa$. However it should be noted that missing responses may not be at random, and it is most likely that those belong to the lower SES groups are actually the ones who are more likely to have missing responses. Thus as a sensitivity analysis, we tested whether results changed by treating pairs of respondent (adolescent and parents) as having consistent responses if both parties had nonresponses. To do so, we generated a separate group for the three SES measures for cases where both the parents and the adolescent had missing responses. For parental education and household income, this new group is ranked as the lowest (since it is reasonable to assume that it is more likely for the low SES households to have missing values for both parties) and weights still applied in calculating the $\kappa$ statistic. For parental occupation, this new group is treated as an independent group in the multinomial variables for occupation. 95\% confidence intervals $(95 \% \mathrm{CI})$ were calculated using the bootstrapping method. A significant difference of $\kappa$ is determined by non-overlapping $95 \% \mathrm{CI}$.

\section{Results}

The distributions of responses by adolescents and parents for parental education, parental occupation and household income are presented in Tables 1 and 2 . Adolescents have higher non-response rate for parental education compared with parent's responses. However, for parental occupation and family income, adolescents actually had lower non-response rate than their parents.

For both adolescents and parents, the highest nonresponse rate was observed for family income, compared with other SES measures. The $\kappa$ statistic showed good 
Table 1 Adolescent and parent's responses for parental SES

\begin{tabular}{|c|c|c|c|c|c|c|}
\hline \multirow[t]{2}{*}{$n=2,593$} & \multicolumn{2}{|l|}{ Father's SES } & \multirow[t]{2}{*}{ Kappa $(95 \% \mathrm{Cl})$} & \multicolumn{2}{|l|}{ Mother's SES } & \multirow[t]{2}{*}{ Kappa $(95 \% \mathrm{Cl})$} \\
\hline & Adolescent & Parent & & Adolescent & Parent & \\
\hline \multicolumn{7}{|l|}{ Parent's education } \\
\hline Primary school or below & 13.7 & 15.0 & $0.86(0.85-0.88)$ & 17.5 & 19.2 & $0.84(0.82-0.86)$ \\
\hline Junior high school & 25.6 & 27.0 & & 25.6 & 27.3 & \\
\hline Senior high school & 24.7 & 15.3 & & 25.6 & 12.3 & \\
\hline 3-year technical school & 7.8 & 14.2 & & 9.9 & 22.7 & \\
\hline 5-year technical school & 6.5 & 11.1 & & 5.4 & 7.6 & \\
\hline University & 10.8 & 10.0 & & 7.9 & 6.1 & \\
\hline Graduate & 3.5 & 2.5 & & 1.3 & 0.9 & \\
\hline Non response & 7.4 & 4.9 & & 6.7 & 3.9 & \\
\hline \multicolumn{7}{|l|}{ Parent's occupation } \\
\hline Managerial & 12.6 & 14.1 & $0.39(0.36-0.41)$ & 4.4 & 7.5 & $0.47(0.45-0.49)$ \\
\hline Professional & 5.9 & 8.2 & & 4.9 & 5.2 & \\
\hline Skilled & 10.3 & 7.9 & & 7.9 & 8.3 & \\
\hline Semi-skilled & 23.5 & 25.8 & & 26.5 & 19.4 & \\
\hline Agricultural & 3.3 & 3.4 & & 0.5 & 0.2 & \\
\hline Low skilled & 26.1 & 25.3 & & 10.9 & 9.1 & \\
\hline Unskilled & 8.1 & 3.7 & & 6.7 & 2.2 & \\
\hline Military & 0.8 & 5.6 & & 0.1 & 0.1 & \\
\hline Unemployed/not in job & 2.5 & 1.3 & & 33.9 & 37.3 & \\
\hline Unable to classify & 0.9 & 2.7 & & 0.4 & 3.6 & \\
\hline Non response & 6.0 & 10.3 & & 3.9 & 12.5 & \\
\hline
\end{tabular}

agreements between the reports by adolescents and by parents for both father and mother's educational attainment levels $(\kappa=0.86,95 \% \mathrm{CI}=0.85-0.88$ and $\kappa=0.84$, $95 \% \mathrm{CI}=0.82-0.86$, respectively). The degree of concordance is lower for parental occupation $(\kappa=0.39,95 \%$ $\mathrm{CI}=0.36-0.41$ and $\kappa=0.47,95 \% \mathrm{CI}=0.45-0.49$, for father's and mother's occupation respectively). For household income, $\kappa=0.44$ (95\% CI $=0.39-0.49)$.

Table 2 Adolescent and parent's responses for household income

\begin{tabular}{clll}
\hline $\mathbf{n}=\mathbf{2 , 5 9 3}$ & Adolescent & Parent & Kappa(95\%Cl) \\
\hline$<$ NT\$30,000 & 16.1 & 10.2 & $0.44(0.39-0.49)$ \\
NT\$30,000-49,999 & 20.2 & 17.6 & \\
NT\$50,000-59,999 & 19.3 & 12.2 & \\
NT\$60,000-69,999 & 6.4 & 7.2 & \\
NT\$70,000-79,999 & 7.6 & 4.4 & \\
NT\$80,000-89,999 & 4.2 & 6.1 & \\
NT\$90,000-99,999 & 4.2 & 2.2 & \\
NT\$100,000-109,999 & 3.4 & 6.5 & \\
NT\$110,000-119,999 & 2.8 & 0.5 & \\
NT\$120,000-129,999 & 1.5 & 1.0 & \\
NT\$130,000-139,999 & 1.0 & 0.4 & \\
NT\$140,000-149,999 & 0.6 & 0.3 & \\
$>$ NT\$150,000 & 3.6 & 3.3 & \\
Non response & 9.2 & 28.2 & \\
\hline
\end{tabular}

US\$1 = NT\$30
The relationship between parent-reported SES and financial stress is shown in Table 3, 4, 5. The results showed that household financial stress is closely associated with the SES variables. For example, out of the parents who reported "surplus" for the financial stress question, $23.9 \%$ of them reported father's education equal or above university (Table 3 ). The corresponding figures for those parents who reported "average" and "shortage" were only $7.5 \%$ and $4.7 \%$ respectively. Similar patterns were observed for maternal education and household income. For parental occupation, a much higher percentage of the parents who reported "surplus" belong to the occupation categories of managerial, profession and skilled occupations.

The degree of concordance for the three SES measures relative to financial stress and relative standard of living from the parent's perception is reported in Table 6. For parental education and occupation, the degree of concordance is the lowest for parents reported highest financial stress. For father's education for example, $\kappa$ decreased from 0.87 (95\% CI $=0.85-0.90)$ for families with surplus in the financial stress question to 0.78 (95\% $\mathrm{CI}=0.66-0.84)$ for those with worst financial balances. The non-overlapping 95\% CI indicates that the decrease in $\kappa$ is statistically significant. Similar pattern was observed for father's occupation (between those who reported surplus and balanced), and mother's occupation (between those who reported surplus and not 
Table 3 Distribution of parent-reported education by financial stress (\%)

\begin{tabular}{|c|c|c|c|c|c|c|c|c|}
\hline \multirow[b]{3}{*}{$\mathrm{n}$} & \multicolumn{4}{|c|}{ Father's education } & \multicolumn{4}{|c|}{ Mother's education } \\
\hline & Surplus & Balanced & Shortage & & Surplus & Balanced & Shortage & \\
\hline & 874 & 1287 & 403 & $p$ & 874 & 1287 & 403 & $p$ \\
\hline Primary school or below & 8.4 & 16.4 & 23.6 & $* *$ & 11.0 & 22.3 & 26.3 & ** \\
\hline Junior high school & 17.5 & 32.3 & 30.5 & & 19.2 & 30.8 & 33.5 & \\
\hline Senior high school & 14.3 & 16.6 & 14.4 & & 11.4 & 13.0 & 12.2 & \\
\hline 3-year technical school & 16.5 & 13.2 & 12.2 & & 27.6 & 20.5 & 19.1 & \\
\hline 5-year technical school & 16.5 & 9.3 & 5.5 & & 13.6 & 5.1 & 3.2 & \\
\hline University & 18.5 & 6.6 & 3.2 & & 12.5 & 3.0 & 2.7 & \\
\hline Graduate & 5.4 & 0.9 & 1.5 & & 2.1 & 0.4 & 0.2 & \\
\hline Non-response & 3.0 & 4.6 & 9.2 & & 2.6 & 4.9 & 2.7 & \\
\hline
\end{tabular}

${ }^{* *} \chi^{2}$ test for difference in distribution by levels of financial stress, $\mathrm{p}<0.000$

enough). Such pattern of decreasing concordance was less significant for the relative standard of living question.

As a sensitivity analysis, we also tested whether the results remain if treating concordance for missing values as a separate group (Tables not shown). The results from this analysis were similar to the ones without missing values.

\section{Discussions}

We found that the degree of concordance for the three SES measures between adolescent and parent reports decreases with higher family financial stress, and the results hold if treating both parties having missing values has concordant.

The role financial stress plays in relation to the traditional SES variables should be discussed. Some suggested that financial stress reflects resources availability, which may not necessarily be captured by the tradition SES measures, as households with similar incomes can show a wide variation in financial stress[15] In addition, financial stress may act as an intermediate factor between the SES and health relationship[29]. However, our data indicated that financial stress is highly correlated with the SES variables in this research, where lower financial stresses were observed for parents with higher education, more skilled jobs and higher household income. This indicates that financial stress may reflect to a large extent the "true" SES of the households. The implication of our results thus is significant: the concordance between the parent and adolescent reported SES variables may be actually determined by the "true" underlying SES of the household. Thus the bias would be larger for higher financial stressed families when estimating the SES gradient for adolescent health. Such bias could arise regardless of whether the SES variables were reported by the parents or by the adolescents.

There are some possible mechanisms for the results found. First, it is possible that adolescents from families with higher financial stress are less aware of the SES situations of the family. For example, it is possible that poor parent-adolescent communication is more prevalent among higher financially stressed families, and hence adolescents were not told about the situations associated with family SES. Second, it is also possible that parents or adolescents from higher financially

Table 4 Distribution of parent-reported parental occupation by financial strain (\%)

\begin{tabular}{|c|c|c|c|c|c|c|c|c|}
\hline & \multirow{2}{*}{\multicolumn{4}{|c|}{$\begin{array}{l}\text { Father's occupation } \\
\text { Surplus Balanced Shortage }\end{array}$}} & \multirow{2}{*}{\multicolumn{4}{|c|}{$\begin{array}{l}\text { Mother's occupation } \\
\text { Surplus Balanced Shortage }\end{array}$}} \\
\hline & & & & & & & & \\
\hline & 874 & 1287 & 403 & $p$ & 874 & 1287 & 403 & $p$ \\
\hline Managerial & 10.5 & 3.7 & 2.7 & $* *$ & 3.7 & 1.1 & 1.5 & ** \\
\hline Professional & 11.7 & 6.4 & 6.7 & & 7.1 & 4.5 & 3.2 & \\
\hline Skilled & 12.2 & 6.4 & 4.0 & & 11.6 & 6.6 & 7.0 & \\
\hline Semi-skilled & 29.8 & 25.3 & 18.6 & & 23.2 & 17.7 & 16.6 & \\
\hline Agricultural & 2.3 & 3.6 & 5.0 & & 0.1 & 0.2 & 0.0 & \\
\hline Low skilled & 17.5 & 28.4 & 32.3 & & 4.2 & 11.2 & 13.2 & \\
\hline Unskilled & 2.2 & 4.4 & 5.0 & & 1.1 & 2.3 & 4.5 & \\
\hline Military & 5.5 & 6.2 & 3.7 & & 0.1 & 0.2 & 0.0 & \\
\hline Unemployed/not in job & 0.5 & 1.2 & 3.2 & & 34.6 & 39.2 & 37.7 & \\
\hline Unable to classify & 2.1 & 2.9 & 3.2 & & 3.9 & 3.3 & 4.2 & \\
\hline
\end{tabular}

${ }^{* *} \chi^{2}$ test for difference in distribution by levels of financial stress, $p<0.000$ US\$1 $=$ NT\$30 
Table 5 Distribution of parent-reported household income by financial stress (\%)

\begin{tabular}{lcccc}
\hline $\mathbf{n}$ & Surplus & Balanced & Shortage & \\
\hline$<N T \$ 30,000$ & $\mathbf{8 7 4}$ & $\mathbf{1 2 8 7}$ & $\mathbf{4 0 3}$ & $\boldsymbol{p}$ \\
\hline NT\$30,000-49,999 & 4.92 & 11.19 & 17.87 & $* *$ \\
NT\$50,000-59,999 & 11.78 & 19.89 & 22.83 & \\
NT\$60,000-69,999 & 9.95 & 14.14 & 10.67 & \\
NT\$70,000-79,999 & 8.92 & 7.3 & 3.72 & \\
NT\$80,000-89,999 & 6.29 & 3.73 & 2.23 & \\
NT\$90,000-99,999 & 9.04 & 5.13 & 3.23 & \\
NT\$100,000-109,999 & 3.89 & 1.55 & 0.5 & \\
NT\$110,000-119,999 & 12.36 & 3.73 & 2.7 & \\
NT\$120,000-129,999 & 1.03 & 0.31 & 0.0 & \\
NT\$130,000-139,999 & 1.95 & 0.54 & 0.3 & \\
NT\$140,000-149,999 & 0.92 & 0.16 & 0.3 & \\
$>N T \$ 150,000$ & 0.69 & 0.16 & 0.0 & \\
Non response & 7.44 & 1.17 & 1.2 & \\
\hline
\end{tabular}

${ }^{* *} \chi^{2}$ test for difference in distribution by levels of financial stress, $p<0.000$

stressed families are more reluctant to report correct SES data. Previous studies have reported that SES is closely related to self-esteem for adolescents [30], showing that adolescents may be sensitive to their family SES conditions and hence may be reluctant to report accurate SES data when SES is low (which could be reflected by higher family financial stress). These mechanisms can be tested by future studies.

We also found that the phenomenon of decrease in concordance was not observed when using relative standard of living. This may indicate that the above proposed mechanisms work more when the household experience actual financial difficulties. This may also explained by the previous findings that people may use different reference group to rate their relative standings, and the ratings are sensitive to different reference groups used[31]. In other words, a parent may report better in the relative standard of living question while another parent with similar SES may report worse, causing the relative standard of living question being less associated with a household's SES situation.

Our results show that concordance for household income is not affected by household financial stress. One obvious explanation is that these two variables are highly related. In other words, parents report their level of financial stress based on household income to a large extent, thus causing less variation of concordance for income when stratified by financial stress.

There are several strengths and weaknesses of this research. In terms of strength, first, though household financial stress and relative standard living may be closely correlated with the three SES measures, the formal two suffer from much less non-responses. The nonresponse rates for the financial stress variables were only about $1 \%$ of the sample. Thus this allows us to test whether concordances of the SES variables are actually affected by a proxy of the "true" SES. Using financial stress has the additional advantage of incorporating factors that are normally not considered when measuring SES (such as whether family members include those with illness, which would reduce available household resources), and hence may be able to better reflect the actual SES condition of the household.

The weakness of this research should also be noted. Like all self-assessed variables, there could be measurement error. For example, a parent may report the household has surplus of income when in fact it does not. For the SES measures, it should also be noted that it is possible that reports by adolescents and parents for the SES measures are both incorrect and hence even a high agreement does not indicate a valid answer. This however, is beyond the scope of this study. In addition, Lien et al.[8] inferred from another study that if both the parent and the children do not report accurately on a particular question, it is more like to be a problem in the response from the family rather than a problem of invalidity caused by the adolescent's lack of understanding of the family situation. Another limitation is that the data used in this study are not very recent. It is possible

Table 6 Kappa statistics for concordance for adolescent and parent reports of SES, by parent reported financial condition

\begin{tabular}{|c|c|c|c|c|c|c|c|c|c|c|c|}
\hline \multirow{2}{*}{\multicolumn{2}{|c|}{$\begin{array}{c}\mathrm{n} \\
\text { Parent reported financial status }\end{array}$}} & \multicolumn{2}{|c|}{ Father education } & \multicolumn{2}{|c|}{ Mother education } & \multicolumn{2}{|c|}{ Father occupation } & \multicolumn{2}{|c|}{ Mother occupation } & \multicolumn{2}{|c|}{ Household income } \\
\hline & & $\kappa$ & $95 \% \mathrm{Cl}$ & $\kappa$ & $95 \% \mathrm{Cl}$ & $\kappa$ & $95 \% \mathrm{Cl}$ & $\kappa$ & $95 \% \mathrm{Cl}$ & $\kappa$ & $95 \% \mathrm{Cl}$ \\
\hline Surplus & 874 & 0.87 & $(0.85-0.90)$ & 0.83 & $(0.76-0.87)$ & 0.42 & $(0.38-0.47)$ & 0.50 & $(0.46-0.55)$ & 0.43 & $(0.35-0.50)$ \\
\hline Balanced & 1,287 & 0.85 & $(0.82-0.87)$ & 0.78 & $(0.75-0.83)$ & 0.34 & $(0.30-0.37)$ & 0.46 & $(0.42-0.50)$ & 0.34 & $(027-0.42)$ \\
\hline Not enough & 403 & 0.78 & $(0.66-0.84)$ & 0.71 & $(0.59-0.80)$ & 0.39 & $(0.31-0.44)$ & 0.40 & $(0.35-0.45)$ & 0.31 & $(0.19-0.42)$ \\
\hline \multicolumn{12}{|l|}{ Parent reported SOL } \\
\hline A lot better/better & 313 & 0.87 & $(0.82-0.90)$ & 0.86 & $(0.80-0.91)$ & 0.39 & $(0.32-0.46)$ & 0.49 & $(0.44-0.57)$ & 0.39 & $(0.28-0.54)$ \\
\hline Average & 1,952 & 0.86 & $(0.83-0.87)$ & 0.81 & $(0.77-0.84)$ & 0.38 & $(0.36-0.41)$ & 0.47 & $(0.44-0.50)$ & 0.39 & $(0.33-0.45)$ \\
\hline Worse/a lot worse & 303 & 0.84 & $(0.70-0.89)$ & 0.66 & $(0.51-0.83)$ & 0.32 & $(0.26-0.39)$ & 0.40 & $(0.34-0.47)$ & 0.36 & $(0.19-0.54)$ \\
\hline
\end{tabular}

Non-response $=29$ for financial strain and 25 for standard of living. 
that individual or societal factors that may influence concordance changed over the past years. It should also be noted that the degree of agreement may not be stable across time, depending on factors such as employment status and feelings of economic security. A solution would be to conduct a test-retest analysis within a period of time. This however, is not available from our data. Finally, the sample used here is representative of Northern Taiwan, and not the entire country. However, Northern Taiwan is of higher SES compared with other parts of the island, and it is reasonable to hypothesize that concordance is higher for the higher SES families. Thus the degree of poor concordance may be underestimated (instead of overestimated).

Several studies found moderate to good concordance between adolescents and parents reports on SES variables such as parental education, parental occupation and household income [6-8,32,33]. Other than the traditional SES measures, a study found good concordance between these two parties on receipt of public assistance [33]. However, whether such concordance influence by household financial stress should be considered. Our results also suggests that in the presence of different levels of financial stress, parental education may still be the most consistent measure of adolescent SES, since its concordance remained higher than other SES variables for all levels of financial stress.

Due to the generally high number of missing values for traditional parental SES variables reported by adolescents, many studies have used the "family affluence scale" (FAS), which included car ownership, telephone ownership and the child having their own unshared bedroom $[11,26]$. The advantage of using such scale is a lower level of missing data. While a adolescent may not know their parent's educational attainment, they are very likely to know whether their family owns a car[10]. It has also been found that the FAS is highly correlated with a country's gross domestic product[26]. Limitations of the FAS have also been proposed. A study argued that results from FAS are generally non-comparable due to variations in cultures and differences in time[8]. For example, the possibility of owning a car may become much higher for now compares with a decade ago. Some also argued that complete measures of SES should cover both resource-based and prestige-based measures [34]. For these reasons, traditional measures of SES should not be replaced by wealth[35]. This research does not intend to discuss the validity of FAS and whether traditional SES measures should be replaced by FAS in measuring SES for adolescents. However, our results point to some new directions for future research in this area. Firstly, there is a need to consider whether consistency between the adolescent's and parent's report on FAS also decreases with financial stress, and whether the results vary by culture and time. Secondly, it is important to determine the mechanisms for the relationship found between the traditional SES measures and household financial stress and standard of living. By doing this, while it will still be difficult to know the true values for the missing data by either the adolescent or their parent, at least one can postulate a possible upward or downward bias in the estimated SES gradients for adolescents.

\section{Conclusions}

Though the agreement between adolescents' and parents' reports on parental education, parental occupation and household income is generally judged to be good by previous research, using adolescents reports for family SES may still be biased if analysis is not stratified by family financial stress, as the degree of concordance for the three SES measures between adolescent and parent reports decreases with higher family financial stress.

\section{Acknowledgements}

This research is partially sponsored by a grant from Ministry of Education, aim for the Top University Plan. Data analyzed in this paper were collected by the research project "Taiwan Youth Project" sponsored by the Academia Sinica (AS-93-TP-C01). This research project was carried out by Institute of Sociology, Academia Sinica, and directed by Dr. Chin-Chun Yi. The Center for Survey Research of Academia Sinica is responsible for the data distribution. The authors appreciate the assistance in providing data by the institutes and individuals aforementioned. The views expressed herein are the authors' own.

\section{Author details}

${ }^{1}$ Institute of Hospital and Health Care Administration, School of Medicine, National Yang-Ming University, Taipei, Taiwan. ${ }^{2}$ Department of Public Health, School of Medicine, National Yang-Ming University, Taipei, Taiwan.

\section{Authors' contributions}

$\mathrm{CP}$ was responsible for data analysis and writing up the manuscript; $\mathrm{NH}$ designed the study and helped in drafting the manuscript. YC coordinated the research and finalized the manuscript. All authors read and approved the final manuscript.

Competing interests

The authors declare that they have no competing interests.

Received: 4 January 2011 Accepted: 19 April 2011

Published: 19 April 2011

\section{References}

1. Petridou E, Zavitsanos X, Dessypris N, Frangakis C, Mandyla M, Doxiadis S, Trichopoulos D: Adolescents in high-risk trajectory: clustering of risky behavior and the origins of socioeconomic health differentials. Prev Med 1997, 26:215-219.

2. Goodman E: The role of socioeconomic status gradients in explaining differences in US adolescents' health. Am J Public Health 1999, 89:1522-1528.

3. Geyer S, Peter R, Siegrist J: Socioeconomic differences in children's and adolescents' hospital admissions in Germany: a report based on health insurance data on selected diagnostic categories. J Epidemiol Community Health 2002, 56:109-114.

4. Blum RW, Beuhring T, Shew ML, Bearinger LH, Sieving RE, Resnick MD: The effects of race/ethnicity, income, and family structure on adolescent risk behaviors. Am J Public Health 2000, 90:1879-1884. 
5. Soteriades ES, DiFranza JR: Parent's socioeconomic status, adolescents' disposable income, and adolescents' smoking status in Massachusetts. Am J Public Health 2003, 93:1155-1160.

6. Pueyo MJ, Serra-Sutton V, Alonso J, Starfield B, Rajmil L: Self-reported social class in adolescents: validity and relationship with gradients in selfreported health. BMC Health Serv Res 2007, 7:151.

7. C Vereecken AV: Measurement of parental occupation: Agreement between parents and their children. Arch Public Health 2003, 61:141-149.

8. Lien N, Friestad C, Klepp Kl: Adolescents' proxy reports of parents' socioeconomic status: How valid are they? J Epidemiol Community Health 2001, 55:731-737.

9. West P, Ewen Speed HS: We Really Do Know What You Do: A Comparison of Reports from 11 Year Olds and Their Parents in Respect of Parental Economic Activity and Occupation. Sociology 2001, 35:539-559.

10. Wardle J, Robb K, Johnson F: Assessing socioeconomic status in adolescents: the validity of a home affluence scale. J Epidemiol Community Health 2002, 56:595-599.

11. Currie CE, Elton RA, Todd J, Platt S: Indicators of socioeconomic status for adolescents: the WHO Health Behaviour in School-aged Children Survey. Health Educ Res 1997, 12:385-397.

12. Mistry RS, Benner AD, Tan CS, Kim SY: Family economic stress and academic well-being among Chinese-American youth: the influence of adolescents' perceptions of economic strain. J Fam Psychol 2009, 23:279-290.

13. Gutman LM, Eccles JS: Financial strain, parenting behaviors, and adolescents' achievement: testing model equivalence between African American and European American single- and two-parent families. Child Dev 1999, 70:1464-1476.

14. Lempers JD, Clark-Lempers DS: Economic hardship, family relationships, and adolescent distress: an evaluation of a stress-distress mediation model in mother-daughter and mother-son dyads. Adolescence 1997, 32:339-356.

15. Szanton SL, Allen JK, Thorpe RJ Jr, Seeman T, Bandeen-Roche K, Fried LP: Effect of financial strain on mortality in community-dwelling older women. J Gerontol B Psychol Sci Soc Sci 2008, 63:S369-374.

16. Lempers JD, Clark-Lempers D: Family economic stress, maternal and paternal support and adolescent distress. J Adolesc 1990, 13:217-229.

17. Hagquist CE: Economic stress and perceived health among adolescents in Sweden. J Adolesc Health 1998, 22:250-257.

18. Yoder KA, Hoyt DR: Family economic pressure and adolescent suicidal ideation: application of the family stress model. Suicide Life Threat Behav 2005, 35:251-264.

19. Murakami K, Miyake Y, Sasaki S, Tanaka K, Ohya Y, Hirota Y: Education, but not occupation or household income, is positively related to favorable dietary intake patterns in pregnant Japanese women: the Osaka Maternal and Child Health Study. Nutr Res 2009, 29:164-172.

20. Winkleby MA, Jatulis DE, Frank E, Fortmann SP: Socioeconomic status and health: how education, income, and occupation contribute to risk factors for cardiovascular disease. Am J Public Health 1992, 82:816-820.

21. Maty SC, Everson-Rose SA, Haan MN, Raghunathan TE, Kaplan GA: Education, income, occupation, and the 34-year incidence (1965-99) of Type 2 diabetes in the Alameda County Study. Int J Epidemiol 2005, 34:1274-1281.

22. Yi C-CC, Chin-Fen, Ying-Hwa Chang: The intergenerational transmission of family values: a comparison between teenagers and parents in Taiwan. Journal of Comparative Family Studies 2004, 35:523-545.

23. Yi C-CW, Chyi-In, Ying-Hwa Chang, Ming-Yi Chang: The Psychological Well-being of Taiwanese Youth: School versus Family Context over the Life Course. International Sociology 2009, 24:397-429.

24. Okosun IS, Choi S, Matamoros T, Dever GE: Obesity is associated with reduced self-rated general health status: evidence from a representative sample of white, black, and Hispanic Americans. Prev Med 2001, 32:429-436.

25. Baron-Epel O, Kaplan G: General subjective health status or age-related subjective health status: does it make a difference? Soc Sci Med 2001, 53:1373-1381

26. Andersen A, Krolner R, Currie C, Dallago L, Due P, Richter M, Orkenyi A, Holstein BE: High agreement on family affluence between children's and parents' reports: international study of 11-year-old children. J Epidemiol Community Health 2008, 62:1092-1094.
27. Maclure M, Willett WC: Misinterpretation and misuse of the kappa statistic. Am J Epidemiol 1987, 126:161-169.

28. Whiteman D, Green A: Wherein lies the truth? Assessment of agreement between parent proxy and child respondents. Int J Epidemiol 1997, 26:855-859.

29. Zimmerman FJ, Katon W: Socioeconomic status, depression disparities, and financial strain: what lies behind the income-depression relationship? Health Econ 2005, 14:1197-1215.

30. Khanlou N: Influences on adolescent self-esteem in multicultural Canadian secondary schools. Public Health Nurs 2004, 21:404-411.

31. Wolff LS, Subramanian SV, Acevedo-Garcia D, Weber D, Kawachi I: Compared to whom? Subjective social status, self-rated health, and referent group sensitivity in a diverse US sample. Soc Sci Med 2010, 70:2019-2028.

32. Ensminger MCFAR, Kang Myungsa, Green Bert, Starfield Marbara, Ryan Sheryl: The Validity of Measures of Socioeconomic Status of Adolescents. Journal of Adolescent Research 2000, 15:394-417.

33. Ridolfo HMA: Factors that influence the accuracy of adolescent proxy reporting of parental characteristics: A research note. Journal of Adolescence 2010.

34. Morris SS, Carletto C, Hoddinott J, Christiaensen LJ: Validity of rapid estimates of household wealth and income for health surveys in rural Africa. J Epidemiol Community Health 2000, 54:381-387.

35. Durkin MS, Islam S, Hasan ZM, Zaman SS: Measures of socioeconomic status for child health research: comparative results from Bangladesh and Pakistan. Soc Sci Med 1994, 38:1289-1297.

Pre-publication history

The pre-publication history for this paper can be accessed here: http://www.biomedcentral.com/1471-2288/11/50/prepub

doi:10.1186/1471-2288-11-50

Cite this article as: Pu et al:: Do agreements between adolescent and parent reports on family socioeconomic status vary with household financial stress? BMC Medical Research Methodology 2011 11:50.

\section{Submit your next manuscript to BioMed Central and take full advantage of:}

- Convenient online submission

- Thorough peer review

- No space constraints or color figure charges

- Immediate publication on acceptance

- Inclusion in PubMed, CAS, Scopus and Google Scholar

- Research which is freely available for redistribution

Submit your manuscript at www.biomedcentral.com/submit
C Biomed Central 